\title{
Evaluation of Serum Bilirubin Level Alterations in Patients Undergoing Cholecystectomy: An Observational Study
}

\author{
Narayan Khare ${ }^{1}$, Indra Singh Sahani ${ }^{2}$ \\ ${ }^{1}$ Assistant Professor, Department of Surgery, Index Medical College, Indore, ${ }^{2}$ Associate Professor, Department of Surgery, \\ Amaltas Institute of Medical Sciences, Dewas \\ Corresponding author: Dr. Indra Singh Sahani, Associate Professor, Department of Surgery, Amaltas Institute of Medical \\ Sciences, Dewas
}

DOI: 10.21276/ijcmsr.2018.3.2.30

How to cite this article: Narayan Khare, Indra Singh Sahani. Evaluation of serum bilirubin level alterations in patients undergoing cholecystectomy: an observational study. International Journal of Contemporary Medicine Surgery and Radiology. 2018;3(2):B124-B126.

\section{A B S T R A C T}

Introduction: The frequency and type of biliary injuries during laparoscopic cholecystectomy vary, and timely diagnosis and management is critical for the well-being of the patient. Alterations in serum lipid profile are known to occur in patients undergoing laparoscopic cholecystectomy. Hence; we planned the present study to investigate the serum bilirubin profile in patients undergoing cholecystectomy.

Material and methods: The present research included investigation of serum bilirubin profile in patients undergoing cholecystectomy. A total of 100 patients undergoing laparoscopic cholecystectomy were included in the present study. Serum bilirubin levels were measured in all the patients preoperatively. Laparoscopic cholecystectomy under constant intraperitoneal pressure $(12 \mathrm{~mm} \mathrm{Hg})$ subsequently was performed in all the patients. Both direct and indirect bilirubin was again estimated after 3 days of surgery to monitor the changes occurring in the liver function. SPSS software was used for analysis of all the results.

Results: We observed that mean preoperative total bilirubin values were $0.82 \mathrm{mg} / \mathrm{dl}$, while mean value on $3^{\text {rd }}$ day postoperatively were found to be $0.89 \mathrm{mg} / \mathrm{dl}$. We didn't observe any significant difference while comparing the preoperative and postoperative bilirubin values.

Conclusion: No significant change occurs in mean serum bilirubin levels in patients who underwent laparoscopic cholecystectomy.

Key words: Bilirubin, Laparoscopic Cholecystectomy

\section{INTRODUCTION}

Ever since the introduction of laparoscopic cholecystectomy, there has been tremendous growth in the knowledge of problems encountered with the procedure. ${ }^{1,2}$ The key to success of this procedure is the thorough knowledge of the difficulties and short comings encountered during the entire surgical protocol. Even though open cholecystectomy has been almost completely substituted by the laparoscopic technique, the possibility for iatrogenic duct damages is greater in the second procedure. ${ }^{3,4}$

The frequency and type of biliary injuries during laparoscopic cholecystectomy vary, and timely diagnosis and management is critical for the well-being of the patient. ${ }^{5}$

Alterations in serum lipid profile are known to occur in patients undergoing laparoscopic cholecystectomy.Ifbilirubin levels are used as predictors, test results must be obtained a few weeks before surgery so that the cholecystectomy patient can be referred to the optimal unit in order to ensure the presence of appropriate equipment and to plan the time required for the procedure. ${ }^{6-7}$

Therefore, keeping all these things in mind, we planned the present study to investigate the serum bilirubin profile in patients undergoing cholecystectomy.

\section{MATERIAL AND METHODS}

The present research was commenced in the department of general surgery of the medical institute and it included investigation of serum bilirubin profile in patients undergoing cholecystectomy. From the institutional ethical committee, we obtained ethical clearance. Written consent was obtained from all the patients after explaining in detail the entire research protocol. A total of 100 patients undergoing laparoscopic cholecystectomy were included in the present study. Inclusion criteria for the present study included:

- Patients planned to undergo laparoscopic cholecystectomy,

- Patients who were willing to give written consent,

- Patients between the age group of 25 to 55 years,

- Patients with absence of any other systemic illness,

- Patients with negative history of any known drug allergy

- Patients with negative history of any form hepatotoxic drug therapy

- Patients with absence of any liver pathology 
We obtained the detailed clinical history along with demographic details of all the patients. Serum bilirubin levels were measured in all the patients preoperatively. Laparoscopic cholecystectomy (LC) under constant intraperitoneal pressure $(12 \mathrm{~mm} \mathrm{Hg})$ subsequently was performed in all the patients. Both direct and indirect bilirubin was again estimated after 3 days of surgery to monitor the changes occurring in the liver function. SPSS software was used for analysis of all the results. One way ANOVA and Chi- square test were used for assessment of level of significance. P- Value of less than 0.05 was taken as significant.

\section{RESULTS}

The present study was conducted on the patients undergoing

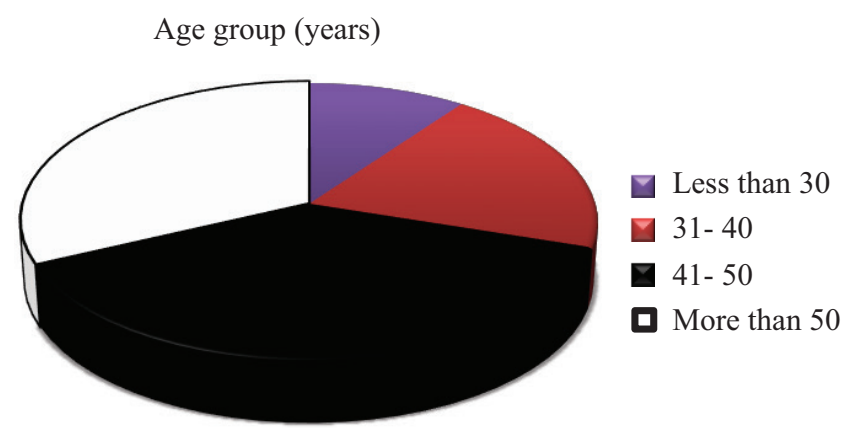

Graph-1: Age-wise distribution of subjects

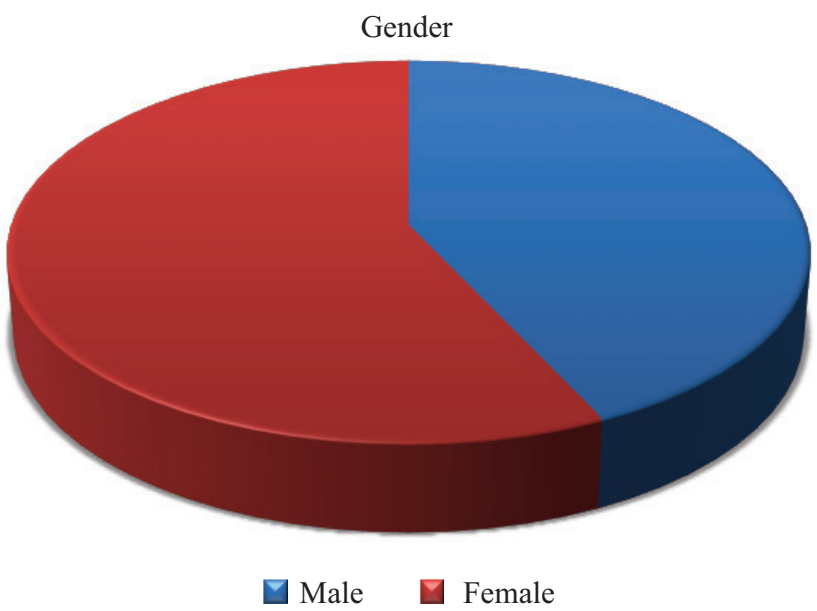

Graph-2: Gender-wise distribution of subjects

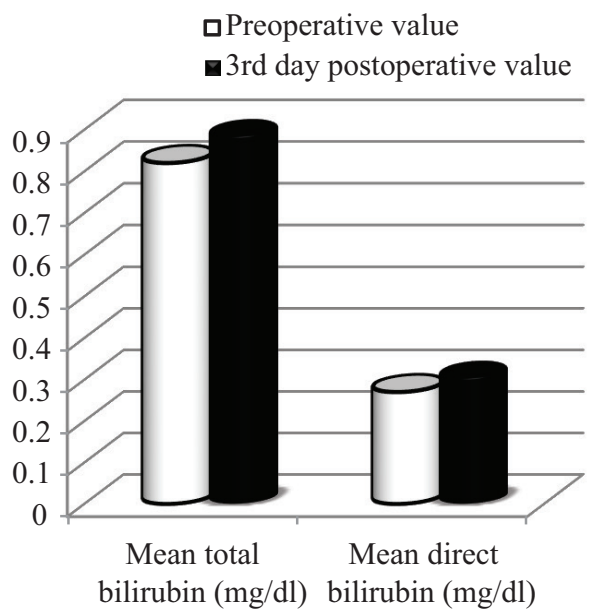

Graph-3: Mean bilirubin values at different time intervals

\begin{tabular}{|c|c|c|c|}
\hline Parameter & $\begin{array}{c}\text { Mean } \\
\text { total } \\
\text { bilirubin } \\
\text { (mg/dl) }\end{array}$ & $\begin{array}{c}\text { Mean } \\
\text { direct } \\
\text { bilirubin } \\
(\mathrm{mg} / \mathrm{dl})\end{array}$ & $\begin{array}{c}\mathrm{P}- \\
\text { value }\end{array}$ \\
\hline Preoperative value & 0.82 & 0.27 & \multirow[t]{2}{*}{0.84} \\
\hline $3^{\text {rd }}$ day postoperative value & 0.89 & 0.31 & \\
\hline
\end{tabular}

Laparoscopic cholecystectomy. We included a total of 100 patients with mean age of 43.5 years. 70 percent of the patients included in the present study were of more than 30 years of age. 57 percent of the patients of the present study were females while the remaining 43 percent were males. We observed that mean preoperative total bilirubin values were $0.82 \mathrm{mg} / \mathrm{dl}$, while mean value on $3^{\text {rd }}$ day postoperatively were found to be $0.89 \mathrm{mg} / \mathrm{dl}$. We didn't observe any significant difference while comparing the preoperative and postoperative bilirubin values.

\section{DISCUSSION}

One of the commonest abdominal surgical procedures performed these days is Cholecystectomy. It involves laparoscopic removal in patients in which cholecystectomy is primary indication. Current investigations are being carried out for exploring the lesser invasive techniques like single incision LC. ${ }^{8,9}$ Past results from various studies have shown that alterations in the hepatic profile occur in patients undergoing LC. ${ }^{10}$ Hence; we planned the present study to investigate the serum bilirubin profile in patients undergoing laparoscopic cholecystectomy.

In the present study, we observed a non- significant alteration in the mean serum bilirubin values in patients undergoing cholecystectomy. Singal R et al compared and correlated the serum level of bilirubin, alanine transaminase (ALT), aspartate transaminase (AST), alkaline phosphatase (ALP) in patients who underwent laparoscopic cholecystectomy to those who underwent OC. A total number of 200 patients diagnosed as cholelithiasis were included in the study. These cases were randomly divided into two groups (A and B) consisting of 100 cases each. In group A patients, LC was carried out, while in group B patients, OC was done. They took blood samples thrice; pre-surgical, one day post-surgical and three days after surgery. Samples were taken thrice for comparing the alterations in the enzymatic levels. They observed significant rise in the serum bilirubin, AST and ALT levels, one day after the surgery, in comparison to preoperative value, in patients undergoing LC. The values returned to approximately normal range after 72 hrs of surgery except in that of ALP. ALP levels showed slight fall after $24 \mathrm{hrs}$ of surgery and then slight rise after $72 \mathrm{hrs}$ which was within the normal limit. Transient elevation of serum bilirubin, AST and ALT occurs after laparoscopic cholecystectomy. ${ }^{11}$ Ahmad NZ evaluated the role of routine testing before and after laparoscopic cholecystectomy. A total of 355 patients were retrospectively analyzed by examining the LFTs the day before, the day after, and 3 weeks after the surgery. Alterations in the serum AST, ALT, and GGT were seen on the first postoperative day. Minor changes were seen in bilirubin and 
ALP. An overall disturbance in the LFTs was seen in more than two-thirds of the cases. Repeat LFTs performed after 3 weeks on follow-up were found to be within normal limits. Mild-to-moderate elevation in preoperative LFTs may not be associated with any deleterious effect, and, in the absence of clinical indications, routine preoperative or postoperative liver function testing is unnecessary. ${ }^{12}$ In another past study conducted by Srivastava PK, authors evaluated the serum Bilirubin levels in subjects undergoing LC. They assessed a total of subjects and carried out routine investigations in them along with evaluation of serum bilirubin profile. After that all patients got their pre-anaesthetic check-up and underwent laparoscopic cholecystectomy. They evaluated the levels of both direct and indirect bilirubin again, three days after the surgery with the purpose of monitoring the alterations in the liver functions. After assessing the results with SPSS software, they observed that mean bilirubin levels (total and direct) were 0.78 and 0.22 respectively. However; they didn't observed any significant difference in the mean bilirubin values while comparing the preoperative and postoperative values in subjects undergoing LC. From the results, the authors concluded that mean bilirubin profile remains unaffected in patients undergoing LC. ${ }^{13}$ In another study, conducted by Al-Luwaizia KR et al, authors evaluated impact of penumoperitoneum on liver enzymes in patients undergoing LC. Further, they also compared the values with the values obtained with open cholecystectomy. Under the light of results, they concluded that significant increase in the liver profile of the patients could be attributed to the adverse effects of the pneumoperitoneum on the hepatic blood flow. ${ }^{14}$ Gupta $\mathrm{R}$ et al, in another previous study assessed the impact of diverse intraperitoneal pressure on liver function tests in patients undergoing LC. A total of 101 gallstone patients were included in their study that was scheduled to undergo LC. They broadly divided the patients into two study groups with 51 patients in each group; highpressure laparoscopic cholecystectomy (HPLC) $(n=51)$ and low-pressure laparoscopic cholecystectomy (LPLC) $(n=50)$ and underwent surgery at pressures of $14 \mathrm{~mm} \mathrm{Hg}$ and $8 \mathrm{~mm}$ $\mathrm{Hg}$, respectively. They performed the various liver functions tests both preoperatively and postoperatively at first day and seventh day.

Total bilirubin values on the first postoperative day were found to be $1.0684 \mathrm{mg} / \mathrm{dL}$ and $0.8926 \mathrm{mg} / \mathrm{dL}$ for HPLC and LPLC, respectively. From the results, they concluded that significant alterations in the liver enzyme activities occur in patients in the HPLC group in comparison with the LPLC group. $^{15}$

\section{CONCLUSION}

Under the light of above results, the authors conclude that no significant change occurs in mean serum bilirubin levels in patients who underwent laparoscopic cholecystectomy. Therefore, further research is recommended in future for better exploration of this field of surgery.

\section{REFERENCES}

1. Yang $\mathrm{MH}$, Chen TH, Wang SE, Tsai YF, $\mathrm{Su} \mathrm{CH}, \mathrm{Wu}$ $\mathrm{CW}$, et al. Biochemical predictors for absence of common bile duct stones in patients undergoing laparoscopic cholecystectomy. Surg Endosc. 2008;22(1):1620-1624.

2. Cuschieri A, Lezoche E, Morino M, Croce E, Lacy A, Toouli J, et al. EAES multicentre prospective randomized trial comparing two-stage vs single-stage management of patients with gallstone disease and ductal calculi. Surg Endosc. 1999;13(3):952-957.

3. Notash AY, Salimi J, Golfam F, Habibi G, Alizadeh K. Preoperative clinical and paraclinical predictors of choledocholithiasis. Hepatobiliary Pancreat Dis Int. 2008;7(3):304-307.

4. Menezes N, Marson LP, Debeaux AC, Muir IM, Auld $\mathrm{CD}$. Prospective analysis of a scoring system to predict choledocholithiasis. Br J Surg. 2000;87(5):1176-1181.

5. Sgourakis G, Dedemadi G, Stamatelopoulos A, Leandros E, Voros D, Karaliotas K. Predictors of common bile duct lithiasis in laparoscopic era. World J Gastroenterol. 2005;11(2):3267-3272.

6. Cohen ME,SlezakL,Wells CK,Andersen DK,Topazian M. Prediction of bile duct stones and complications in gallstone pancreatitis using early laboratory trends. Am J Gastroenterol. 2001;96(4):3305-3311.

7. Urbach DR, Khajanchee YS, Jobe BA, Standage BA, Hansen PD, Swanstrom LL. Cost-effective management of common bile duct stones: a decision analysis of the use of endoscopic retrograde cholangiopancreatography (ERCP), intraoperative cholangiography, and laparoscopic bile duct exploration. Surg Endosc. 2001;15(6):4-13.

8. van Santvoort HC, Bakker OJ, Besselink MG, Bollen TL, Fischer K, Nieuwenhuijs VB, et al. Dutch Pancreatitis Study Group. Prediction of common bile duct stones in the earliest stages of acute biliary pancreatitis. Endoscopy. 2011;43(3):8-13.

9. Hasukić S. Postoperative changes in liver function tests: randomized comparison of low- and highpressure laparoscopic cholecystectomy. Surg Endosc. 2005;19(11):1451-5.

10. Kaldor A, Akopian G, Recabaren J, Alexander M.Utility of liver function tests after laparoscopic cholecystectomy. Am Surg. 2006;72(12):1238-40.

11. Singal R, Singal RP, Sandhu K, et al. Evaluation and comparison of postoperative levels of serum bilirubin, serum transaminases and alkaline phosphatase in laparoscopic cholecystectomy versus open cholecystectomy. Journal of Gastrointestinal Oncology. 2015;6(5):479-486.

12. Ahmad NZ. Routine Testing of Liver Function Before and After Elective Laparoscopic Cholecystectomy: Is It Necessary? JSLS : Journal of the Society of Laparoendoscopic Surgeons. 2011;15(1):65-69.

13. Srivastava PK. Estimation of alterations occurring in the bilirubin profile of patients undergoing cholecystectomy: a comparative study. International Journal of Contemporary Medicine Surgery and Radiology. 2018;3(1):82-84.

14. Al-Luwaizia KR,Hamadb SO. Changes of liver enzymes and serum bilirubin after laparoscopic cholecystectomy. Ann Coll Med Mosul 2013; 39 (2): 113-117.

15. Gupta R1, Kaman L, Dahiya D, Gupta N, Singh R. Effects of varying intraperitoneal pressure on liver function tests during laparoscopic cholecystectomy. J Laparoendosc Adv Surg Tech A. 2013;23(4):339-42. 